\title{
Oral Bisphosphonate-induced Osteonecrosis of Jaw: A Case Report
}

\author{
Neha Verma ${ }^{1}$, Adit Srivastava ${ }^{2}$
}

\begin{abstract}
Osteonecrosis of bone is a debilitating condition resulting from avascularity of bone. Bisphosphonates which are routinely used in treating bone disorders like osteoporosis and certain malignancies have been associated with increased incidence of osteonecrosis of bone, commonly affecting jaws. Though dental trauma has been a predisposing factor, certain patients have shown spontaneous development of osteonecrosis on long term administration of bisphosphonates.
\end{abstract}

Keywords: Necrotic bone, Necrotic bone hyperbaricoxygen, Osteonecrosis bisphosphonate, Osteonecrosis jaw bisphosphonate. Journal of Oral Health and Community Dentistry (2019): 10.5005/jp-journals-10062-0043

\section{INTRODUCTION}

B sphosphonates have been revolutionary in treating hypercalcemia of malignancy, bone metastases, multiple myeloma Paget's disease, osteogenesis imperfecta but it's been most valuable in treating osteoporosis in postmenopausal women.' Bisphosphonates are anti-resorptive, pyrophosphate analogs, efficient in inhibiting bone resorption. They bind to hydroxyapatite of bone are released during bone remodeling. ${ }^{2}$ Bisphosphonaterelated osteonecrosis of the jaw (BRONJ) is a serious debilitating side effect of this therapy commonly seen with intravenous administration. ${ }^{3}$ According to American Society for Bone and Mineral Research "Bisphosphonate-associated ONJ is defined as an area of exposed bone in the maxillofacial region that does not heal within 8 weeks after identification by a healthcare provider, in a patient who is receiving or has been exposed to a bisphosphonate and has not had radiation therapy to the craniofacial region. Additional signs and symptoms may include pain, swelling, paraesthesia, suppuration, soft tissue ulceration, intra- or extraoral sinus tracks, loosening of teeth, and radiographic variability". ${ }^{4}$

According to the American Association of Oral and Maxillofacial Surgeons, (AAOMS), diagnostic criteria for BRONJ include:

- Bone exposure in the maxillofacial region for a period longer than 8 weeks.

- Previous or current treatment with bisphosphonate.

- No previous history of radiotherapy on the jaws. ${ }^{5}$

BRONJ commonly affects mandible due to less vascularity than the maxilla. Bisphosphonate-induced osteonecrosis is diagnosed mainly on clinical and radiographic findings, and a tissue biopsy is indicated in cases of metastasis. ${ }^{6}$

\section{Case report}

A 60-year-old female patient reported in the department with a complaint of pain and swelling in the right mandibular region for 3 months (Fig. 1). The patient was on corticosteroid (Defcort) 9 mg, Hydroxychloroquine $200 \mathrm{mg}$ for systemic lupus erythematosus for 6 years and Ibandronic acid (Bisphosphonate) $150 \mathrm{mg}$ for osteoporosis since 2 years. The patient was edentulous with a history of extraction 3 years back and was wearing denture since then. She discontinued wearing denture 4 months back due to pain in the right mandibular region. On extra oral examination, diffuse swelling was present extending from
${ }^{1}$ Senior Resident, ${ }^{2}$ Associate Professor

1,2Department of Oral Medicine and Radiology, Faculty of Dental Sciences, IMS, BHU, Varanasi, Uttar Pradesh, India

Corresponding Author: Adit Srivastava, Associate Professor, Department of Oral Medicine and Radiology, Faculty of Dental Sciences, IMS, BHU, Varanasi, Uttar Pradesh, India, e-mail: dr.adit69@ gmail.com

How to cite this article: Verma N, Srivastava A. Oral Bisphosphonateinduced Osteonecrosis of Jaw: A Case Report. J Oral Health Comm Dent 2019;13(1):27-29.

Source of support: Nil

Conflict of interest: None

right inferior border of the mandible to submandibular region of the same side. Intraorally patient was completely edentulous. Ulceration along with exposed necrotic bone was seen in the right mandibular vestibular region with respect to 46,47 , and 48 (Fig. 2). Orthopantomogram revealed erosion of cortical bone with ill-defined borders in the alveolar crest of the lower left teeth 44 extending to the retromolar region of the same side (Fig. 3). Computerd tomography (CT) showed ill-defined irregularly marginated soft tissue density lesion involving lingual surface of

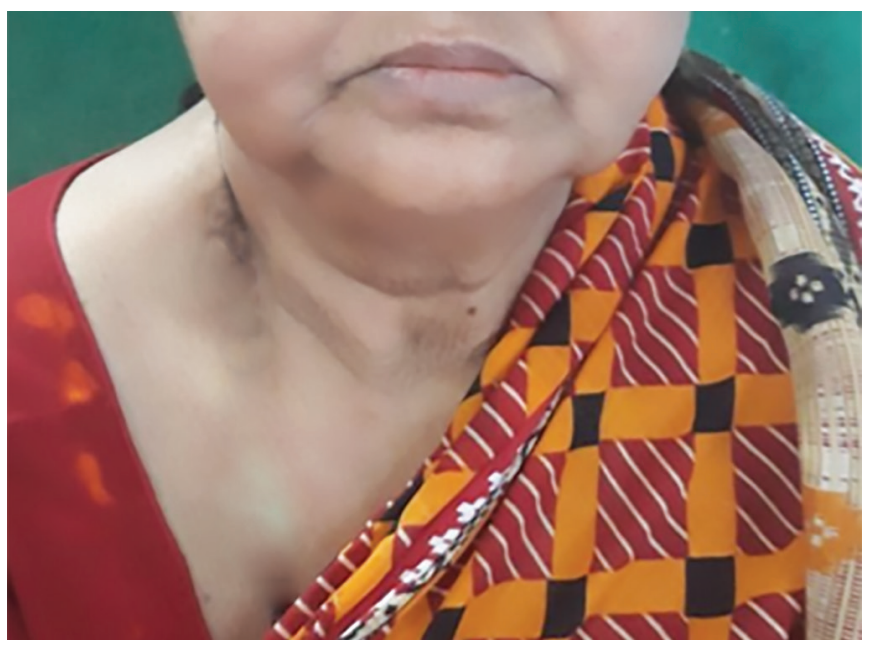

Fig. 1: Extraoral photograph showing swelling in right mandibular body region

(0) The Author(s). 2019 Open Access This article is distributed under the terms of the Creative Commons Attribution 4.0 International License (http://creativecommons. org/licenses/by/4.0/), which permits unrestricted use, distribution, and non-commercial reproduction in any medium, provided you give appropriate credit to the original author(s) and the source, provide a link to the Creative Commons license, and indicate if changes were made. The Creative Commons Public Domain Dedication waiver (http://creativecommons.org/publicdomain/zero/1.0/) applies to the data made available in this article, unless otherwise stated. 


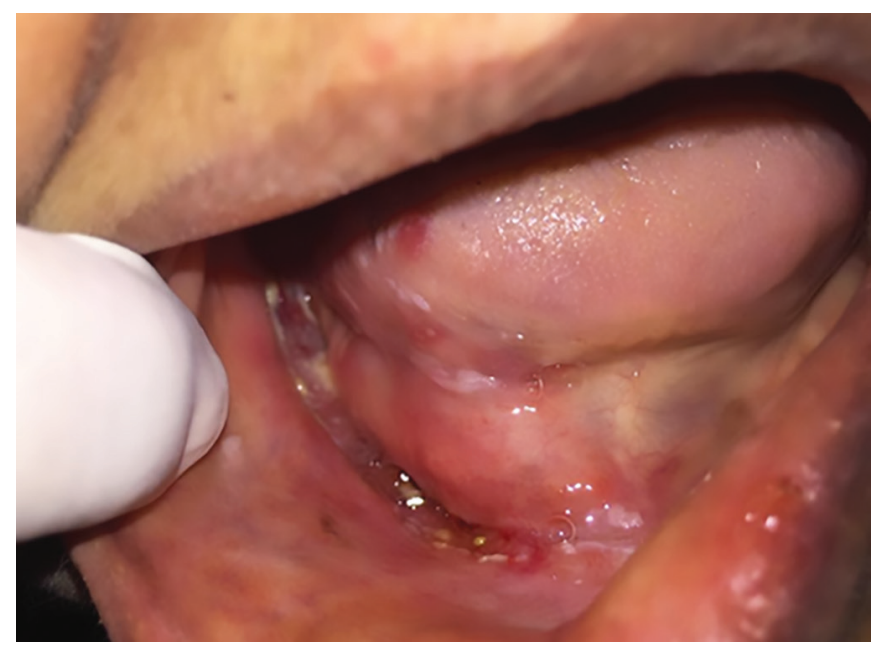

Fig. 2: Exposed necrotic bone right gingivobuccal sulcus

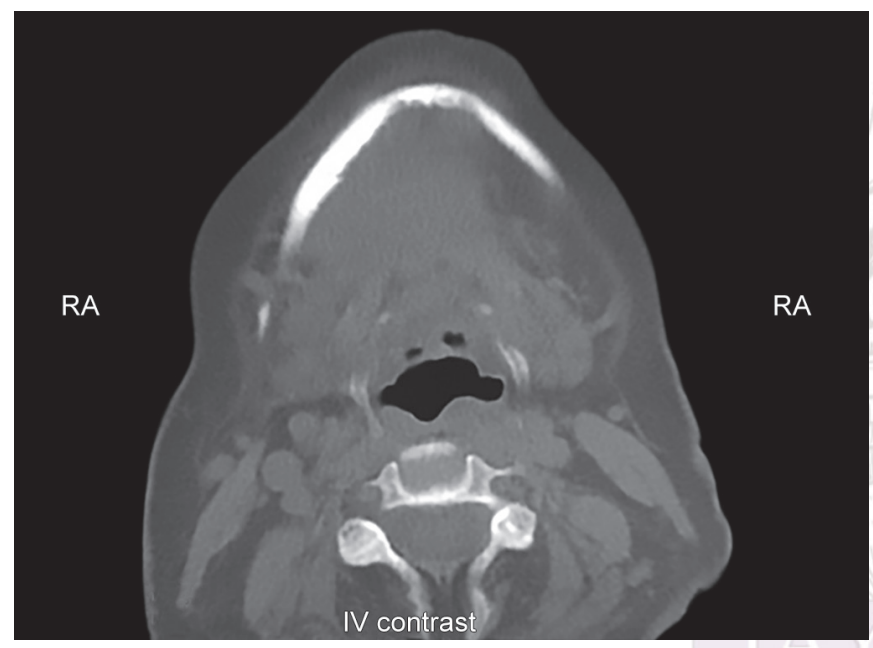

Fig. 4: CT axial view showing ill defined irregularly marginated soft tissue density lesion

lower gingivobuccal sulcus on the right side (Figs 4 and 5). Based on history, clinical and radiological examination diagnosis of stage Il bisphosphonate-induced osteonecrosis of the jaw was made. The patient was treated for necrosis with mechanical debridement, irrigation with hydrogen peroxide, iodopovidone, and $1 \%$ chlorhexidine gel done twice a week. She was instructed to maintain oral hygiene, disinfect mouth after meals with $0.2 \%$ chlorhexidine solution and hydrogen peroxide rinses. Metronidazole with chlorhexidine ointment was given for topical application. She was kept on antibiotic therapy for 14 days consisting of amoxicillin and clavulanic acid ( $1 \mathrm{gm} /$ day) and metronidazole (600 mg/day). The patient reported a reduction in pain and inflammation after 10 days. She was planned for hyperbaric oxygen therapy later for which she did not report.

\section{Discussion}

Bisphosphonates are antiresorptive drugs targeting osteoclasts specifically. They promote proliferation and differentiation of osteoblast and inhibit osteoclasts. Bisphosphonates resist breakdown by enzymatic hydrolysis thus accumulating in the bone matrix and having a long half-life. They affect the formation of the ruffled border by

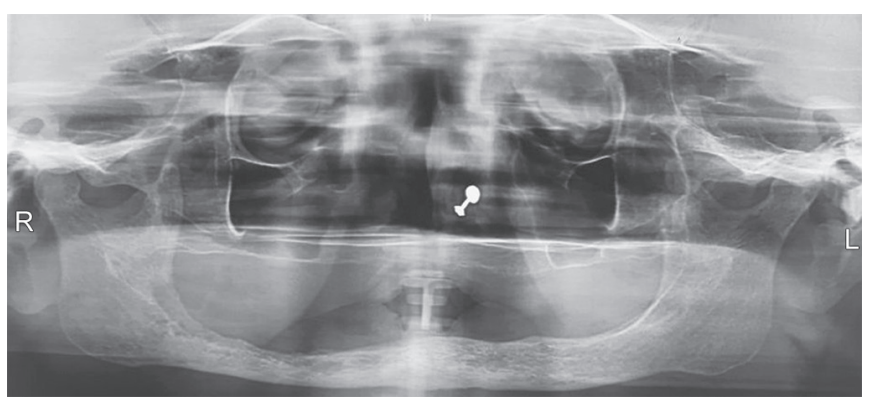

Fig. 3: Erosion of cortical bone with ill defined borders in the alveolar crest of the lower left teeth 44 extending to retro molar region

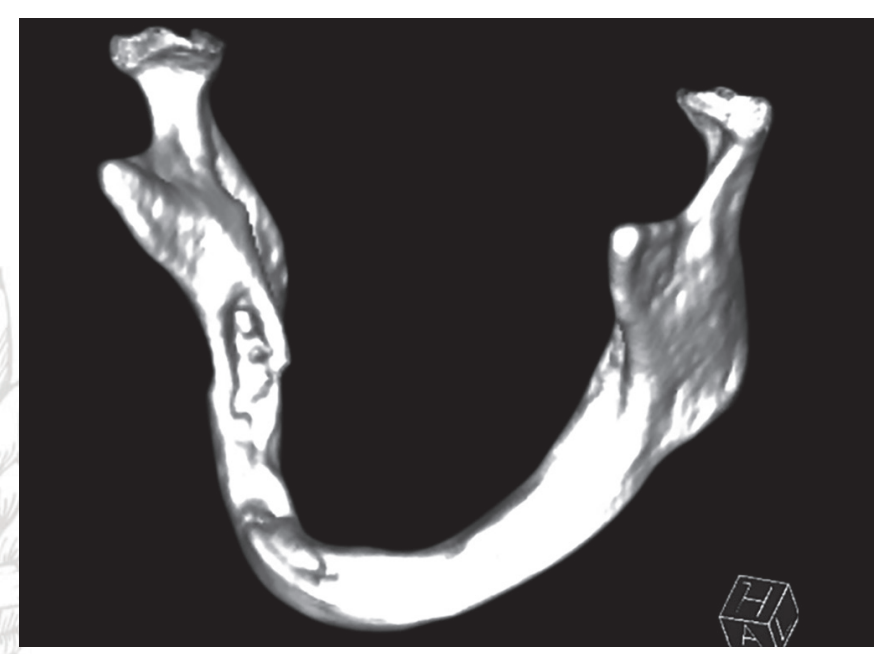

Fig. 5: 3D reconstruction showing erosion of cortical plate of right side

osteoclasts and their adherence to bony surface resulting in decreased bone resorption activity. ${ }^{7}$ Studies have shown higher incidence of BRONJ when bisphosphonates are administered intravenously than orally due to its decreased bioavailability on oral administration, ${ }^{8}$ however our patient showed clinical manifestation of disease in shorter duration of oral administration due to corticosteroids which further increased its rate of progression. BRONJ is associated with the history of recent dental trauma; our patient gave no history of any such recent event. This was a rare case of spontaneous development of disease in the absence of underlying cause of dental trauma. The treatment approach for BRONJ is determined by the stage of disease progression. A surgical intervention like sequestrectomy and resective or segmental surgery remains the mainstay treatment modality in BRONJ patients with extensive involvement or with associated symptoms. Conservative management with the maintenance of oral hygiene, periodic dental check-up, chlorhexidine mouthwashes, and antibiotic treatment, is indicated in patients who are at risk or without symptoms. ${ }^{9}$ Hyperbaric Oxygen has shown efficacy in the treatment of BRONJ. It stimulates cell proliferation, promotes soft tissue healing and reduces pain. ${ }^{10}$ Low-intensity laser therapy (LILT) can be a beneficial alternative in treating BRONJ patients. Laser therapy has shown a reduction in pain, improved healing, and nerve regeneration. ${ }^{11}$ Pentoxifylline and $a$-tocopherol have been promising adjuvant to antibiotics; have shown a reduction in exposed bone area and other symptoms. ${ }^{12}$

According to an expert panel consisting of American Association of oral and maxillofacial surgeons taskforce on BRONJ, patients should receive necessary dental treatment and prophylaxis 
before starting with bisphosphonate therapy to reduce the risk of dental trauma inciting osteonecrosis in jaws later.

Patients who are on bisphosphonate therapy are divided into three groups:

- Group 1: Individuals who take oral therapy for less than three years and have not any further clinical risk factors.

- Group 2: Individuals who take oral therapy for less than three years and had also taken corticosteroids concomitantly.

- Group 3: Patients who take therapy for more than three years with or without concomitant steroids.

Patients in group 1 can undergo routine dental and surgical procedures without modification whereas for groups 2 and 3 conservative management should be considered over surgical procedures. If the patient is showing improvement in condition for which bisphosphonate was prescribed, bisphosphonate therapy should be discontinued for 3 months before oral surgical procedures and continued only after osseous healing has taken place. Patients with dental implants should be monitored regularly for peri implantitis. ${ }^{13}$

\section{Conclusion}

Bisphosphonates have shown efficacy in treatment though with serious complications like BRONJ. Patients on bisphosphonates should be regularly screened for any such development and oral examination with all invasive dental procedures should be performed before initiation of bisphosphonate therapy to reduce risk from dental trauma.

\section{References}

1. American Association of Oral and Maxillofacial Surgeons Position Paper on Bisphosphonate-Related Osteonecrosis of the Jaws. Advisory Task Force on Bisphosphonate-Related Osteonecrosis of the Jaws. J Oral Maxillofacial Surg 2007; 65:369-376.
2. Rodan GA, Fleisch HA. Bosphosphonates: mechanisms of action. J Clin Invest 1996;97:2692-2696.

3. Nozari LB, Pacheco VN, Freddo AL, etal. Prevalence of bisphosphonaterelated osteonecrosis of the jaws associated with dental extraction: systematic review. J Dent Maxillofacial Res 2018;1(2):72-77.

4. Khosla S, Burr D, Cauley J, et al, for the American Society for Bone and Mineral Research. Bisphosphonate-associated osteonecrosis of the jaw: report of a task force of the American Society for Bone and Mineral Research. J Bone Miner Res 2007;22:1479-1491.

5. American Association of Oral and Maxillofacial Surgeons position paper on bisphosphonate-related osteonecrosis of the jaws. J Oral Maxillofac Surg 2007;5(3):369-376.

6. Beninati F, Pruneti R, Ficarra G. Bisphosphonate-related osteonecrosis of the jaws (Bronj). Med Oral Patol Oral Cir Bucal 2013 Sep 1;18 (5):e752758.

7. Rasmusson L, Abtahi J. Bisphosphonate associated osteonecrosis of the jaw: an update on pathophysiology, risk factors, and treatment. International Journal of Dentistry 2014;2014.

8. Kim YG, Lee BS, Kwon YD, et al. Study on bisphosphonate-related osteonecrosis of the jaw (BRONJ): case report and literature review. J Korean Assoc Oral Maxillofac Surg. 2010 Aug;36(4):291-302.

9. Rodriguez-Lozano FJ, Oñate-Sánchez RE. Treatment of osteonecrosis of the jaw related to bisphosphonates and other antiresorptive agents. Med Oral Patol Oral Cir Bucal 2016 Sep;21(5): e595-e600.

10. Ripamonti $\mathrm{Cl}$, Cislaghi E, Mariani L, et al. Efficacy and safety of medical ozone $(\mathrm{O}(3))$ delivered in oil suspension applications for the treatment of osteonecrosis of the jaw in patients with bone metastases treated with bisphosphonates: Preliminary results of a phase I-II study. Oral Oncol 2011;47:185-190.

11. Atalay B, Yalcin S, Emes Y, et al. Bisphosphonate-related osteonecrosis: laser-assisted surgical treatment or conventional surgery? Lasers Med Sci. 2011;26:815-823.

12. Magremanne M, Reychler H. Pentoxifylline and tocopherol in the treatment of yearly zoledronic acid-related osteonecrosis of the jaw in a corticosteroid-induced osteoporosis. J Oral Maxillofac Surg 2014;72:334-337.

13. Baraldi A, Fusco V, Bellora A, et al. Prevention of bisphosphonatesinduced osteonecrosis. Clin Cases Miner Bone Metab 2007;4(1):58-61. 